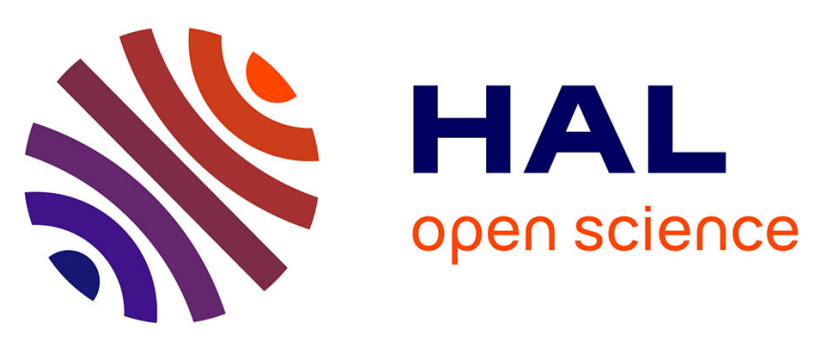

\title{
Plasma based concept for engineering of multifunctional materials with application to synthesis of large-area plasmonic substrates and to control the charge injection in dielectrics
}

Kremena Makasheva, Bernard Despax, Christian Laurent, Laurent Millière, Christina Villeneuve-Faure, Caroline Bonafos, Alessandro Pugliara, Robert Carles, Laurent Boudou, G. Teyssedre

\section{- To cite this version:}

Kremena Makasheva, Bernard Despax, Christian Laurent, Laurent Millière, Christina VilleneuveFaure, et al.. Plasma based concept for engineering of multifunctional materials with application to synthesis of large-area plasmonic substrates and to control the charge injection in dielectrics. 2016 IEEE 16th International Conference on Nanotechnology (IEEE-NANO), Aug 2016, Sendai, Japan. pp.8-11, 10.1109/NANO.2016.7751389 . hal-02324467

\section{HAL Id: hal-02324467 \\ https://hal.science/hal-02324467}

Submitted on 1 Nov 2019

HAL is a multi-disciplinary open access archive for the deposit and dissemination of scientific research documents, whether they are published or not. The documents may come from teaching and research institutions in France or abroad, or from public or private research centers.
L'archive ouverte pluridisciplinaire HAL, est destinée au dépôt et à la diffusion de documents scientifiques de niveau recherche, publiés ou non, émanant des établissements d'enseignement et de recherche français ou étrangers, des laboratoires publics ou privés. 


\title{
Plasma based concept for engineering of multifunctional materials with application to synthesis of large-area plasmonic substrates and to control the charge injection in dielectrics*
}

\author{
Kremena Makasheva, Member, IEEE, Bernard Despax, Christian Laurent, Fellow, IEEE, \\ Laurent Milliere, Christina Villeneuve-Faure, Caroline Bonafos, Alessandro Pugliara, Robert Carles, \\ Laurent Boudou, and Gilbert Teyssedre, Member, IEEE
}

\begin{abstract}
The proposed approach in this contribution concerns plasma deposition processes for engineering of multifunctional materials. It opens the way for transition from material level of development to system level of applications. This concept is applied for deposition of nanocomposite thin layers comprising a single layer of silver nanoparticles (AgNPs) embedded in silica-like host matrices at a controlled distance from the free surface with application in two distinguished fields, namely plasmonics to obtain large-area plasmonic embedded substrates and electrical engineering to control the charge injection in dielectrics. Structural, optical and electrical characterizations of the samples confirm the process efficiency.
\end{abstract}

\section{INTRODUCTION}

Versatility of plasma based deposition processes is widely used for technological purposes [1]. Starting in the early 80's in the microelectronics domain, the plasma enhanced chemical vapor deposition (PECVD) processes have now place in different areas of our every day's life, like for example in optics for coating films, for surface treatment in the food industry, for biomedical applications, in photovoltaics' domain, etc. Depending on the type of operated gas discharge, the main plasma parameters (electron density and electron energy), the reactive gases used as precursors and gas pressure, one can obtain a large variety of composition of the deposits, including nanocomposites [2]. The possibility to design complex nanocomposite thin layers is determined by the complexity of the medium itself. The properties of non-equilibrium plasmas as media actually represent key elements in the synthesis of nanocomposite thin films offering a high degree of freedom in their elaboration.

RF capacitively coupled discharges are by far the most widely applied ones for thin film depositions, entirely compatible with the microelectronic technology. Moreover, in hybrid plasma deposition methods, by combining PECVD and sputtering, nanoparticles can also be composed of the sputtered material [3, 4]. Such systems thus represent interesting building blocks for the deposition of multifunctional, nanocomposite thin films. To take benefit of

*This work was financially supported by the Agence Nationale de la Recherche in France, project ANR-InTail under contract ANR-AA-PBLI-II2011 and project ADAGIO under contract ANR-11-IDEX-0002-02 of the Program Transversalité 2013, IDEX of the University of Toulouse.

K. Makasheva, B. Despax, C. Laurent, L. Milliere, C. Villeneuve-Faure, A. Pugliara, L. Boudou and G. Teyssedre are with LAPLACE laboratory, Université de Toulouse; CNRS, UPS, INPT; 118 route de Narbonne, F31062 Toulouse, France (e-mail: makasheva@laplace.univ-tlse.fr,).

C. Bonafos, A. Pugliara and R. Carles are with "Nano-optics and nanomaterials for optics" group-CEMES-CNRS, Université de Toulouse, 29 Jeanne Marvig, BP 94347, F-31055 Toulouse, France. the hybrid plasma deposition when the sputtered target is a silver material we have developed a strategy to elaborate large-area plasmonic substrates. The same nanocomposite layers can also be applied in other domains, as presented below, which actually approve their multifunctionality.

It is generally acknowledged that silver nanoparticles (AgNPs) realize the best nanoscale antenna for amplifying local electronic and vibrational signals in the visible range. Therefore, nanocomposite materials consisting of AgNPs embedded in dielectric matrices present a huge interest as plasmonic substrates. The main advantage of these assemblies is the possibility to manipulate, localize and enhance the electromagnetic field at the structure surface [5, 6]. The plasmonic coupling with light enlarges the range of useful optical phenomena, like Localized Surface Plasmon Resonance (LSPR) and Surface-Enhanced Raman Scattering (SERS), all having potential applications as ultra-sensitive sensors for chemical and biomolecular detection and analysis, photonic switches, etc. Development of solid SERS substrates based on metal nanostructures covered by a polymer [7] or inorganic [8] layers (ultrathin $\mathrm{SiO}_{2}$ layer) adds value to the stability, reusing and performance of these substrates. However, the major drawback for the large application of SERS substrates remains the limit imposed by their fabrication. It is due to the drastic requirements for controlling on large area, and in a reproducible way, a welldefined spacing between the metallic nanostructures and the probing molecules deposited on the surface of the plasmonic substrates. Plasma based deposition processes can successfully come to the aid of these issues.

In the electrical engineering domain, the phenomenon of charge injection in dielectric layers under electrical stress is at the origin of space charge formation. For many industrial purposes, like for high voltage DC (HVDC) applications (e.g. HVDC cables with polymeric insulation), the space charge must be avoided because it gives a contribution to the electric field distribution by modifying the latter compared to the designed one and represents a risk for breakdown, especially under voltage reversal [9-11]. To bring a solution to this problem our strategy is based on the idea that owing to the intrinsic difficulty in controlling the contact between polymeric material and a metal (or a semi-conductor made of carbon loaded polymer), one can use a thin layer of a material with adequate properties in between the electrode and the polymer to counteract the injection process to the material defects or traps. This layer contains a single layer of AgNPs (when below the percolation threshold) embedded in an organosilicon matrix. Due to the ability of AgNPs to store 
electrical charges they are supposed to play the role of deep trapping centers thereby stabilizing the injection, implying thus a field reduction at the electrode when the nanograins are charged. The control of charge injection phenomenon certainly improves the performance and increases the reliability of dielectric materials.

The focus of the present study is application of a plasma deposition process to tailor the surface of dielectric materials by a multifunctional layer for elaboration of large-area plasmonic embedded substrates and for formation of barrier layer to control the charge injection in dielectrics. Obtained results on the structural, optical and electrical properties of the samples confirm the plasma process efficiency and the layers' multifunctionality.

\section{EXPERIMENTAL PART}

\section{A. Description of the plasma process}

To accomplish deposition of multifunctional layers we have used an axially asymmetric RF $(13.56 \mathrm{MHz})$ capacitively coupled discharge maintained at low gas pressure [4]. The RF-driven top electrode (smaller, $10 \mathrm{~cm}$ in diameter) was placed in front of a bottom electrode (larger, $12 \mathrm{~cm}$ in diameter) with a gap distance equals to $3.5 \mathrm{~cm}$. The bottom electrode and the walls were grounded. The axially asymmetric design of that RF discharge produces axially asymmetric plasma inducing a self-bias voltage $\left(\mathrm{V}_{\mathrm{dc}}\right)$ on the powered electrode. The self-bias voltage results from the DC voltage drop between the bulk plasma and the electrodes across the plasma sheaths connecting the driven electrode to the ground. It is negative in the usual case. Since the voltage drop across the sheaths is inversely proportional to the sheath capacitances, the sheath with smaller area (smaller electrode) has smaller capacitance inducing thus higher self-bias voltage on the adjacent electrode. The self-bias voltage scales up, in modulus, with the injected power, at a constant pressure and is at the origin of the acceleration of argon ions towards the silver target to achieve bombardment. The most appropriate way to follow the plasma behavior in order to relate it to the plasma deposits is through optical emission spectroscopy of the plasma glow emission as the line intensities increase with either the electron energy or the electron density. The evolution of line intensity ratio of $\mathrm{I}_{\mathrm{Ag}(546.6 \mathrm{~nm})}$ to $\mathrm{I}_{\mathrm{Ar}(549.6 \mathrm{~nm})}$ gives an image of the Ag-amount in the plasma which is related to the Ag-volume fraction deposited on the substrate; the higher the line intensity ratio, the higher the Ag-volume fraction is. The variation of the line intensity ratio $\left(\mathrm{I}_{\mathrm{Ag}(546.6 \mathrm{~nm})} / \mathrm{I}_{\mathrm{Ar}(549.6 \mathrm{~nm})}\right)$ as a function of the injected power or the gas pressure is recorded for each deposition. A set of charts is created during the plasma diagnostic phase that later on is used during the deposition process as it constitutes useful data to obtain reproducible results.

The deposition was performed in two-step process: silver sputtering to obtain the single layer of AgNPs followed by plasma polymerization to create the dielectric cover matrix. The examples given in this work are for sputtering time of $5 \mathrm{~s}$ for a plasma maintained in pure argon at pressure of $p=5.4 \mathrm{~Pa}$ with RF power of $P=80 \mathrm{~W}\left(\mathrm{~V}_{\mathrm{dc}}=-1000 \mathrm{~V}\right)$. The presented dielectric layers to cover the AgNPs are of plasma organosilicon deposit $\left(\mathrm{SiO}_{\mathrm{x}} \mathrm{C}_{\mathrm{y}}: \mathrm{H}\right)$ or plasma silica $\left(\mathrm{SiO}_{2}{ }^{\text {plasma }}\right)$. They were obtained in the same reactor with argonhexamethyldisiloxane (HMDSO, $\left[\mathrm{CH}_{3}\right]_{6} \mathrm{Si}_{2} \mathrm{O}$ ) mixture for the
$\mathrm{SiO}_{\mathrm{x}} \mathrm{C}_{\mathrm{y}}: \mathrm{H}$ layer and with Ar-HMDSO-O $\mathrm{O}_{2}$ mixture for the $\mathrm{SiO}_{2}{ }^{\text {plasma }}$ layer at total gas pressures of $p_{\text {tot }}=6.6 \mathrm{~Pa}$ and $7.7 \mathrm{~Pa}$, and input powers of $P=80 \mathrm{~W}$ and $120 \mathrm{~W}$, respectively. A strong originality of this process is the pulsed injection of HMDSO which allows fine tuning of the plasma properties; hence elaboration of high quality plasma silica layers. For both layers the thickness was controlled through the deposition time. More details on the reactor, the plasma process, the deposition procedure, and the plasma input parameters are given elsewhere $[4,12,13]$

\section{B. Structural, optical and electrical characterizations}

The structural characterization of the obtained samples was performed by applying various diagnostic methods. The nanostructured dielectric layers were visualized by Transmission Electron Microscopy (TEM) in cross-sectional (XS-TEM) and plane view (PV-TEM). Specimens transparent to electrons have been prepared according to a standard procedure: mechanical polishing and $\mathrm{Ar}^{+}$ion milling. The observations were performed using a field emission TEM, FEI Tecnai ${ }^{\text {TM }}$ F20 microscope operating at $200 \mathrm{kV}$, equipped with a spherical aberration corrector and the Gatan Imaging Filter (GIF) TRIDIEM. The Fourier Transform Infrared (FTIR) spectra were acquired with a Brucker Vertex 70 spectrometer in the range $400-4000 \mathrm{~cm}^{-1}$ to get the composition of plasma cover layers. Thicknesses of the nanostructures were determined by spectroscopic ellipsometry using a SOPRA GES-5 ellipsometer in the range $250-850 \mathrm{~nm}$ with an incident angle of $75^{\circ}$.

The optical response of elaborated plasmonic substrates was analyzed through reflectivity measurements. The spectra were recorded with a Varian Cary 5000 spectrophotometer in the range $200-800 \mathrm{~nm}$ in quasi normal incidence.

Space charge measurements were realized using the pulsed electroacoustic (PEA) method [14] equipped with the conventional semi-conducting (SC) electrode (a thermoplastic polymer doped with carbon black particles) connected to the DC supply and an aluminum electrode connected to the ground. Application of a pulsed voltage on the sample induces a displacement of the charges around their position under Coulomb effect. As result elementary pressure waves, issued from each charged zone, with amplitude proportional to the local charge density propagate inside the sample with the speed of sound. To record the acoustic signal, the response of the PEA was averaged for typically $3 \times 10^{4}$ pulses of $600 \mathrm{~V}$ in amplitude. Taking into account the frequency of the pulse generator $(1 \mathrm{kHz})$ a space charge profile was acquired in $30 \mathrm{~s}$. The spatial resolution of the measurement is $25 \mu \mathrm{m}$. The PEA cell was installed in a thermo-stated oven in order to control the temperature at $25^{\circ} \mathrm{C}$. The DC voltage protocol applied to the sample consisted in a step-wise increase of the voltage level, in steps of $5 \mathrm{kV} / \mathrm{mm}$ applied for $20 \mathrm{~min}$ followed by $20 \mathrm{~min}$ period of depolarization. The voltage polarity was defined with reference to the SC electrode. After the last positive voltage step at $+50 \mathrm{kV} / \mathrm{mm}$, the voltage polarity was reversed to -40 $\mathrm{kV} / \mathrm{mm}$ with subsequent increase to $-50 \mathrm{kV} / \mathrm{mm}$ following the same protocol. PEA profiles were recorded every $30 \mathrm{~s}$ in the polarization and depolarization steps at each voltage level and a map showing the space charge dynamics was reconstructed from the different profiles. 


\section{RESULTS AND DISCUSSIONS}

\section{A. Tuning the structural properties of the nanocomposite thin layer}

The overall structure of a typical multifunctional layer elaborated according the above described plasma process is shown in Fig. 1. The bright field XS-TEM (Fig. 1a) and PVTEM (Fig. 1b) images allow for quantification of the layer properties (nanocomposite layer thickness, size and density of the AgNPs). For the used sputtering conditions the obtained single layer of AgNPs deposited on thermal $\mathrm{SiO}_{2}$ layer (as shown in Fig. 1) is not percolated. It is characterized by AgNPs of mean size of $19.6 \pm 7.8 \mathrm{~nm}$ and density of $1.7 \times 10^{11} \mathrm{NPs} / \mathrm{cm}^{2}$, having a shape of prolate spheroid.
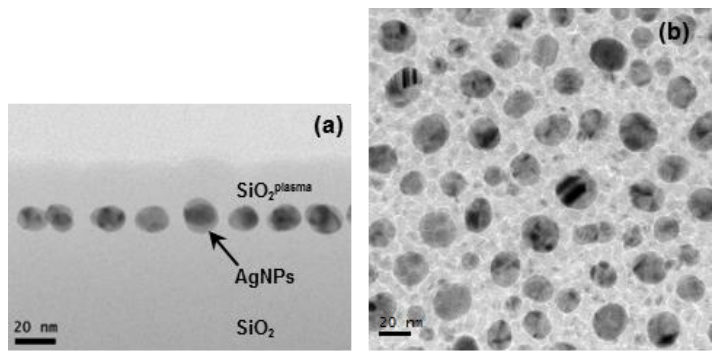

Figure 1. Bright field TEM images of $\mathrm{SiO}_{2}$ layer tailored with a single layer of AgNPs embedded in a plasma deposited $\mathrm{SiO}_{2}{ }^{\text {plasma }}$ matrix: (a) XS-TEM image and (b) PV-TEM image.

By varying the plasma parameters one can adapt the multifunctional layer to the targeted application. The cover layer can be of either $\mathrm{SiO}_{\mathrm{x}} \mathrm{C}_{\mathrm{y}}: \mathrm{H}$ or $\mathrm{SiO}_{2}{ }^{\text {plasma }}$, including a smooth transition between the two compositions.

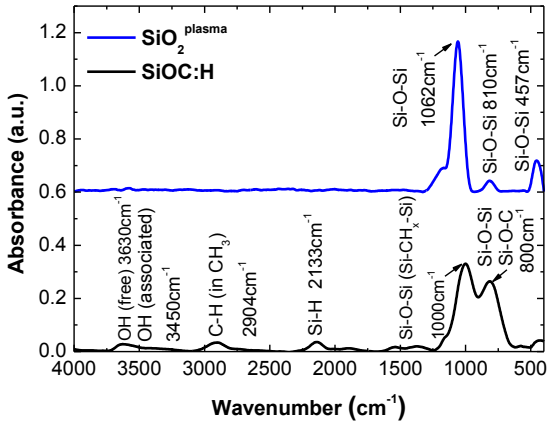

Figure 2. FTIR spectra of plasma deposited silica $\left(\mathrm{SiO}_{2}{ }^{\text {plasma }}\right)$ and organisilicon $\left(\mathrm{SiO}_{\mathrm{x}} \mathrm{C}_{\mathrm{y}}: \mathrm{H}\right)$ cover layers used in this study.

As given in Fig. 2, the obtained $\mathrm{SiO}_{2}{ }^{\text {plasma }}$ is of high quality. Its FTIR spectrum represents only the three typical transversally optic (TO) modes of molecular vibrations of amorphous silica (Si-O-Si rocking vibration at $457 \mathrm{~cm}^{-1}$, the symmetric stretching mode at $810 \mathrm{~cm}^{-1}$, and the asymmetric stretching mode at $1062 \mathrm{~cm}^{-1}$ ) and the shoulder centered around $1250 \mathrm{~cm}^{-1}[12,15]$. The matrix of organosilicon layer $\left(\mathrm{SiO}_{\mathrm{x}} \mathrm{C}_{\mathrm{y}}: \mathrm{H}\right)$ is much less ordered presenting two broad massifs centered around $800 \mathrm{~cm}^{-1}$ and $1000 \mathrm{~cm}^{-1}[4,16,17]$. Because of the high applied power for sustaining the plasma, the HMDSO is strongly dissociated which leads to appearance of the asymmetric stretching band $\mathrm{Si}-\mathrm{H}$ at $2133 \mathrm{~cm}^{-1}$ in the $\mathrm{SiO}_{\mathrm{x}} \mathrm{C}_{\mathrm{y}}: \mathrm{H}$ layer spectrum. Given the difference in the gas mixtures (addition of $\mathrm{O}_{2}$ ) when depositing the layers, one should underline efficiency in the oxidation process during the $\mathrm{SiO}_{2}$ plasma layer growth.

\section{B. Optical response of the obtained plasmonic substrates}

To obtain the plasmonic substrates the nanocomposite layer presented here was deposited on thermal $\mathrm{SiO}_{2}$ layer of thickness of $90 \mathrm{~nm}$ intending highly pronounced antireflectivity properties $[6,18]$.

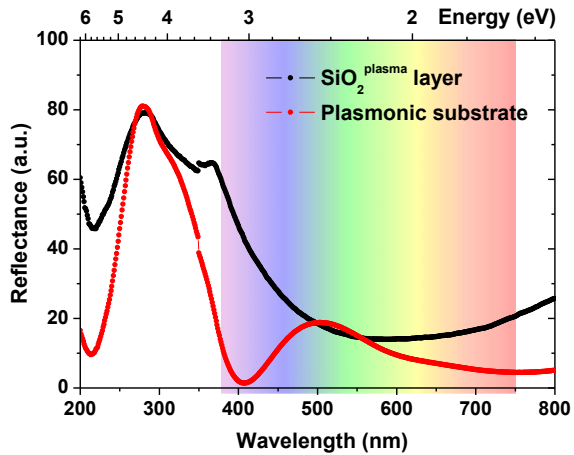

Figure 3. Reflectance spectra of $\mathrm{SiO}_{2}{ }^{\text {plasma }}$ layer (thickness $d_{\mathrm{SiO2plasma}}=$ $96 \mathrm{~nm}$, black line) and plasmonic substrate containing a single layer of AgNPs deposited with $P=80 \mathrm{~W}$ for sputtering time $t_{\mathrm{s}}=5 \mathrm{~s}$. The deposition time of the $\mathrm{SiO}_{2}{ }^{\text {plasma }}$ coverlayer is $t_{\mathrm{d}}=60 \mathrm{~s}\left(d_{\text {SiO2plasma }}=13 \mathrm{~nm}\right)$. Total thickness of the plasmonic substrate is of $100 \mathrm{~nm}$.

Reflectance spectra of $\mathrm{SiO}_{2}{ }^{\text {plasma }}$ layer only and of the plasmonic substrate comprising a single layer of AgNPs localized at $13.0 \mathrm{~nm}$ from the surface of the plasma silica layer are shown in Fig. 3. Presence of AgNPs in the structure drastically affects the reflectance in the visible range (400$750 \mathrm{~nm}$ ) where the applications of plasmonic substrates are expected. The strong absorption at the LSPR (near $413 \mathrm{~nm}$ ) combined with the antireflective effect (around $600 \mathrm{~nm}$ ) is a direct consequence of the design and the performance of the plasma deposits. The elaborated plasmonic substrates thus appear promising for LSPR and SERS based spectroscopies.

\section{Charge injection control in electrically insulating polyethylene}

The performance of the nanocomposite layer with regards to the control of charge injection was tested on a polymer substrate for applied electric fields well above the usual service fields for HVDC applications. Additive-free low density polyethylene (LDPE) samples with thickness of $260 \pm 10 \mu \mathrm{m}$ were prepared by press molding LDPE pellets.
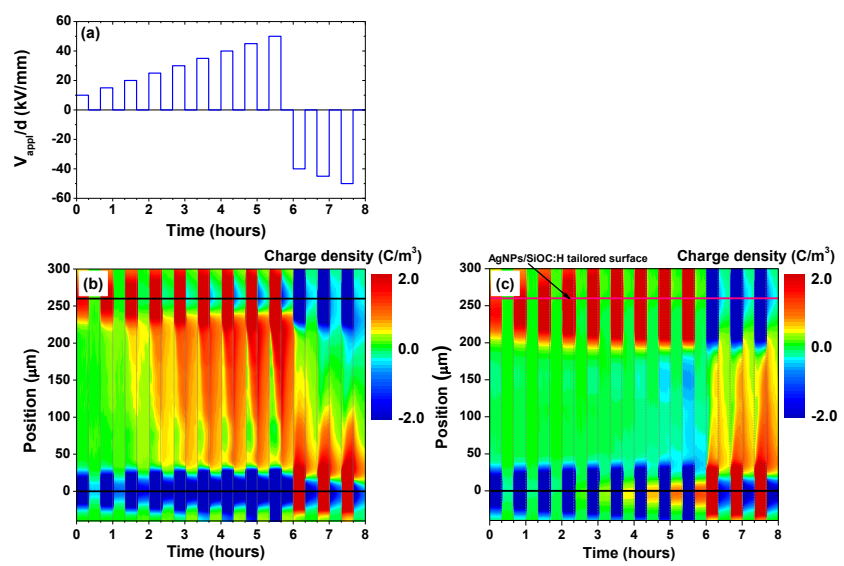

Figure 4. (a) Voltage application protocol for the PEA measurements; Space charge density map in (b) the reference LDPE sample, Al-electrode at $\mathrm{z}=0 \mu \mathrm{m}$, SC-electrode at $\mathrm{z}=260 \mu \mathrm{m}$, the color bar provides charge density scale and in (c) $\mathrm{AgNPs} / \mathrm{SiO}_{\mathrm{x}} \mathrm{C}_{\mathrm{y}}: \mathrm{H}$ tailored LDPE sample. Position of the nanocomposite layer is shown by an arrow. 
The nanocomposite layer consisting of $\mathrm{AgNPs} / \mathrm{SiO}_{\mathrm{x}} \mathrm{C}_{\mathrm{y}}: \mathrm{H}$ stack (54.0 nm thick) was deposited on one side of the LDPE sample. Although the sample surface state changes from polar (for the $\mathrm{SiO}_{2}$ sample used for plasmonic substrates) to apolar in nature (for the LDPE sample for HVDC applications) significant difference in the organization of the single AgNPs layer was not observed. The same mean size and density of AgNPs were observed. Nevertheless, precautions for permanent cooling of the LDPE sample were taken during the plasma process in order to prevent LDPE from thermally induced modifications, like recrystallization and film deformation.

The space charge distribution dynamics is shown on Fig. 4 along with the protocol of the applied voltages in the PEA measurements. Positive injection from the SC-electrode is clearly revealed in the reference LDPE (Fig. 4b), for $+30 \mathrm{kV} / \mathrm{mm}$ and above, with a front of positive charge propagating towards the cathode (Al-electrode) during voltage application. The injected charge density increases with increasing the applied voltage. The space charge distribution is dominated by injection, as revealed by the development of homocharge region (charges of the same sign as the adjacent electrode) in the LDPE bulk. It is also consistent with already reported in the literature data where the SC/LDPE contact is described as being much more efficient injector for positive charge carriers than the Al/LDPE [19]. Upon polarity reversal, positive injection from the Al-electrode dominates the space charge distribution.

When the LDPE surface is tailored by a nanocomposite layer comprising a single layer of AgNPs embedded in organosilicon matrix a drastic difference is observed (Fig. 4c); the most impressive feature being the absence of positive charge injection from the SC-electrode up to $+50 \mathrm{kV} / \mathrm{mm}$. In this case of efficient suppression of charge injection by the nanocomposite layer in contact with the SCelectrode, one can observe the small charge density injected by the Al-electrode for electric fields above $+30 \mathrm{kV} / \mathrm{mm}$. The $\mathrm{AgNPs} / \mathrm{SiO}_{\mathrm{x}} \mathrm{C}_{\mathrm{y}}: \mathrm{H}$ stack also appears quite efficient barrier against negative charges injection. Upon polarity reversal (Fig. 4c, $-40 \mathrm{kV} / \mathrm{mm}$ ), considered as the most damaging situation in the HVDC applications as the applied electric field is amplified by the residual space charge during the previous polarization $(-5 \mathrm{kV} / \mathrm{mm}$ as calculated from the space charge profile during the depolarization phase after polarization at $+50 \mathrm{kV} / \mathrm{mm}$ ), the studied nanocomposite layer efficiently traps the injected negative charges. The charge trapping in both polarities is mainly due to the ability of AgNPs to store positive or negative charges [16]. The organosilicon matrix guarantees the transport of injected charges to the AgNPs permanent traps.

\section{CONCLUSION}

In addition to the above described applications, plasma mediated multifunctional layers of the kind can also be considered for application in advanced solar cells by combining the plasmonic and charge trapping effects [20].

\section{REFERENCES}

[1] M. A. Lieberman and A. J. Lichtenberg, Principle of Plasma Discharges and Materials Processing, Hoboken, New Jersy: John Wiley \& Sons, Inc., 2005.

[2] U. Kortshagen, "Nonthermal plasma synthesis of semiconductor nanocrystals," J. Phys. D: Appl. Phys., vol. 42, p. 113001 (2009).

[3] E. Kay and M. Hecq, "Metal clusters in plasma polymerized matrices: gold," J. Appl. Phys., vol. 55, pp. 370-374, 1984.

[4] B. Despax and P. Raynaud, "Deposition of "Polysiloxane" Thin Films Containing Silver Particles by an RF Asymmetrical Discharge," Plasma Process. Polym., vol. 4, pp. 127-134, 2007.

[5] M. Rycenga, C. M. Cobley, J. Zeng, W. Li, C. H. Moran, Q. Zhang, D. Qin, and Y. Xia, "Controlling the Synthesis and Assembly of Silver Nanostructures for Plasmonic Applications," Chem. Rev., vol. 111, pp. 3669-3712, 2011.

[6] R. Carles, C. Farcau, C. Bonafos, G. BenAssayag, M. Bayle, P. Benzo, J. Groenen and A. Zwick, "Three Dimensional Design of Silver Nanoparticle Assemblies Embedded in Dielectrics for Raman Spectroscopy Enhancement and Dark-Field Imaging," ACS NANO, vol. 5, pp. 8774-8782, 2011.

[7] A. Pal, D. L. Stokes, J.-P. Alarie and T. Vo-Dinh, "Selective SurfaceEnhanced Raman Spectroscopy Using a Polymer-Coated Substrate," Anal. Chem., vol. 67, pp. 3154-3159, 1995.

[8] W. B. Lacy, J. M. Williams, L. A. Wenzler, T. P. Beebe Jr., and J. M. Harris, "Characterization of $\mathrm{SiO}_{2}$-Overcoated Silver-Island Films as Substrates for Surface-Enhanced Raman Scattering," Anal. Chem., vol. 68, pp. 1003-1011, 1996.

[9] J.P. Jones, J.P. Llewellyn, and T.J. Lewis, "The contribution of field induced morphological change to the electrical aging and breakdown of polyethylene", IEEE Trans. Diel. Electr. Insul., vol. 12, pp. 951-966, 2005.

[10] S. Delpino, D. Fabiani, G.C. Montanari, C. Laurent, G. Teyssedre, P.H.F. Morshuis, R. Bodega, and L.A. Dissado, "Polymeric HVDC cable design and space charge accumulation. Part 2: insulation interfaces", IEEE Electr. Insul. Mag., vol. 24, No. 1, pp. 14-24, 2008.

[11] T. T. N. Vu, G. Teyssedre, B. Vissouvanadin, S. Le Roy, and C. Laurent, "Correlating Conductivity and Space Charge Measurements in Multi-dielectrics under Various Electrical and Thermal Stresses," IEEE Trans. Diel. Electr. Insul., vol. 22, pp. 117-127, 2015.

[12] A. Pugliara, C. Bonafos, R. Carles, B. Despax, and K. Makasheva, "Controlled elaboration of large-area plasmonic substrates by plasma process," Material Research Express, vol. 2, p. 065005, 2015.

[13] L. Milliere, K. Makasheva, C. Laurent, B. Despax, and G. Teyssedre, "Efficient barrier for charge injection in polyethylene by silver nanoparticles/plasma polymer stack," Appl. Phys. Lett., vol. 105, p. 122908, 2014.

[14] T. Maeno, T. Futami, H. Kushibe, T. Takada, and C. M. Cooke, "Measurement of spatial charge distribution in thick dielectrics using the pulsed electroacoustic method," IEEE Trans. Dielectr. Electr. Insul., vol. 23, pp. 433-439, (1988).

[15] C. T. Kirk, "Quantitative analysis of the effect of disorder-induced mode coupling on infrared absorption in silica," Phys. Rev. B, vol. 38, pp. 1255-1273, 1988.

[16] L. Milliere, K. Makasheva, C. Laurent, B. Despax, L. Boudou, and G. Teyssedre, "Silver nanoparticles as a key feature of a plasma polymer composite layer in mitigation of charge injection into polyethylene under dc stress," J. Phys. D: Appl. Phys., vol. 49, p. 015304, 2016.

[17] K. Makasheva, C.Villeneuve-Faure, C.Bonafos, C. Laurent, A. Pugliara, B. Despax, L. Boudou, and G. Teyssedre, "Dielectric engineering of nanostructured layers to control the transport of injected charges in thin dielectrics," IEEE Trans. Nanotechnology, 2016, submitted.

[18] M. Bayle, P. Benzo, N. Combe, C. Gatel, C. Bonafos, G. BenAssayag, and R. Carles, "Experimental investigation of the vibrational density of states and electronic excitations in metallic nanocrystals," Phys. Rev. B, vol. 89, p. 195402, 2014.

[19] G. Chen, Y. Tanaka, T. Takada, and L. Zhong, "Effect of Polyethylene Interface on Space Charge Formation", IEEE Trans. Dielectr. Electr. Insul., vol. 11, pp. 113-121, 2004.

[20] H. Choi, W. T. Chen, and P. V. Kamat, "Know Thy Nano Neighbor. Plasmonic versus Electron Charging Effects of Metal Nanoparticles in Dye-Sensitized Solar Cells," ACS NANO, vol. 6, pp. 4418-4427, 2012. 